\title{
Correction to: Estimating heavy metals absorption efficiency in an aqueous solution using nanotube-type halloysite from weathered pegmatites and a novel Harris hawks optimization-based multiple layers perceptron neural network
}

\author{
Bui Hoang Bac ${ }^{1,2} \cdot$ Hoang Nguyen $^{3,4}\left(\right.$ Nguyen Thi Thanh Thao $^{1} \cdot$ Vo Thi Hanh ${ }^{2,5} \cdot$ Le Thi Duyen $^{2,5}$. \\ Nguyen Tien Dung ${ }^{1} \cdot$ Nguyen Khac $\mathrm{Du}^{1} \cdot$ Nguyen Huu Hiep $^{2,6}$
}

Published online: 22 July 2021

(c) Springer-Verlag London Ltd., part of Springer Nature 2021

\section{Correction to: Engineering with Computers https://doi.org/10.1007/s00366-021-01459-8}

In the original version of the paper, the authors used Fig. 1 to describe the geological map of the study site. Unfortunately, some symbols in the original version were incorrect, and they were not match with the main text. Furthermore, the study site has not been shown in the geological map of the original version. Therefore, Fig. 1 was corrected as below:

The original article has been corrected.

The original article can be found online at https://doi.org/10.1007/ s00366-021-01459-8.

Bui Hoang Bac

buihoangbac@humg.edu.vn

$\triangle$ Hoang Nguyen

nguyenhoang@humg.edu.vn

1 Department of Exploration Geology, Faculty of Geosciences and Geoengineering, Hanoi University of Mining and Geology, 18 Vien St., Duc Thang Ward, Bac Tu Liem Dist., Hanoi, Vietnam

2 Centre for Excellence in Analysis and Experiment, Hanoi University of Mining and Geology, 18 Vien St., Duc Thang Ward, Bac Tu Liem Dist., Hanoi, Vietnam

3 Department of Surface Mining, Mining Faculty, Hanoi University of Mining and Geology, 18 Vien St., Duc Thang Ward, Bac Tu Liem Dist., Hanoi 100000, Vietnam
4 Innovations for Sustainable and Responsible Mining (ISRM) Group, Hanoi University of Mining and Geology, 18 Vien St., Duc Thang Ward, Bac Tu Liem Dist., Hanoi 100000, Vietnam

5 Department of Chemistry, Faculty of Basic Science, Hanoi University of Mining and Geology, 18 Vien St., Duc Thang Ward, Bac Tu Liem Dist., Hanoi, Vietnam

6 Department of Geology, Faculty of Geosciences and Geoengineering, Hanoi University of Mining and Geology, 18 Vien St., Duc Thang Ward, Bac Tu Liem Dist., Hanoi, Vietnam 


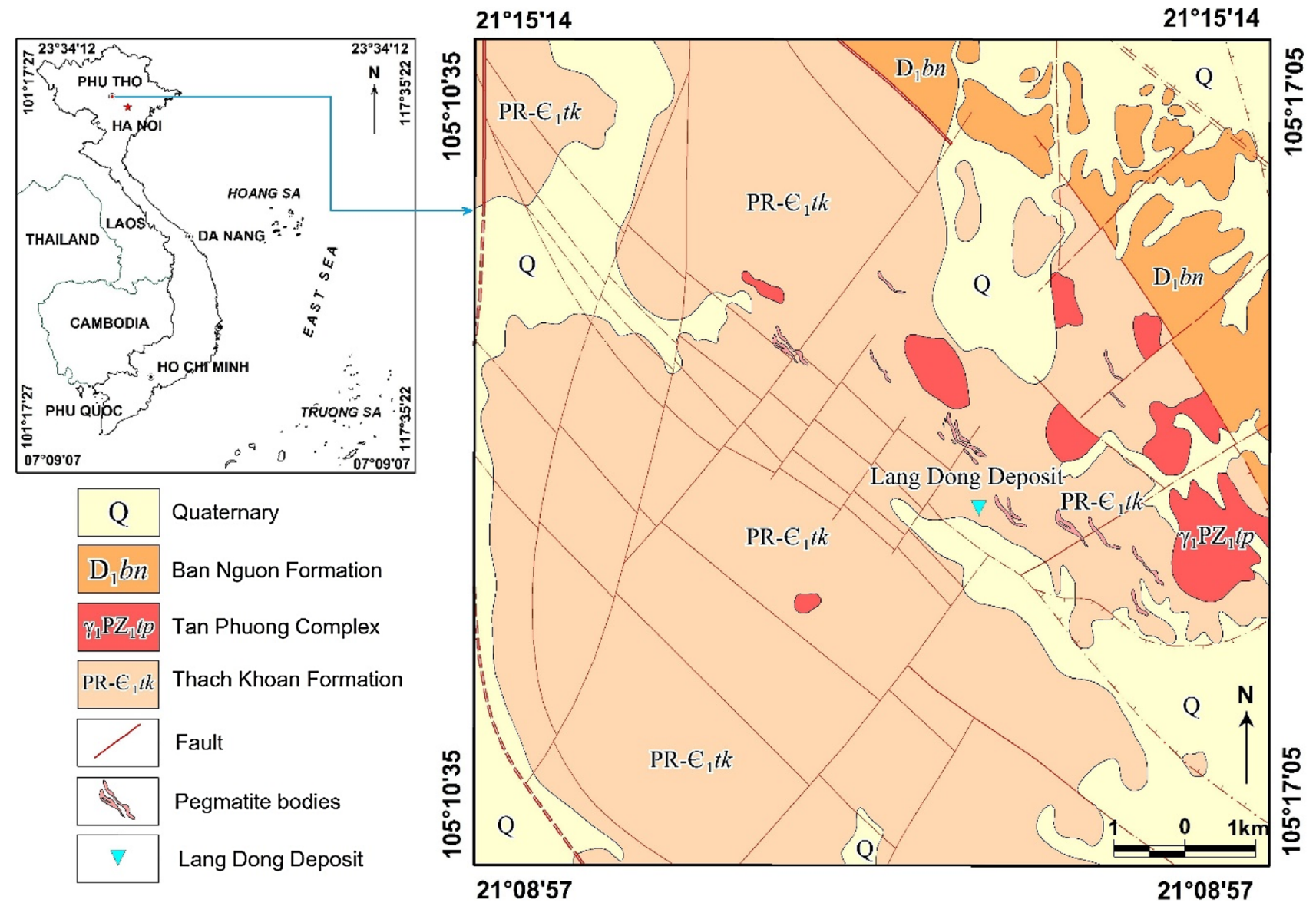

Fig. 1 Geological map of Thach Khoan area 